\title{
Characteristics of Archived Coagulase Negative Staphylococci Isolates at a University Hospital, Nairobi, Kenya
}

\author{
Shivachi Patricia Ingato1, Andrew Nyerere Kimang'a1', Geoffrey Omuse², Samuel Kariuki³, \\ Revathi Gunturu'2, Victor Dinda 4 \\ ${ }^{1}$ Jomo Kenyatta University of Agriculture and Technology, Itromid KEMRI, Nairobi, Kenya \\ ${ }^{2}$ Aga Khan University Hospital, Nairobi, Kenya \\ ${ }^{3}$ Centres for Microbiology Research, KEMRI, Nairobi, Kenya \\ ${ }^{4}$ Masinde Muliro University of Science and Technology, Nairobi, Kenya \\ Email: ingatopatricia@gmail.com
}

Received 4 October 2014; revised 3 November 2014; accepted 1 December 2014

Copyright (C) 2014 by authors and Scientific Research Publishing Inc.

This work is licensed under the Creative Commons Attribution International License (CC BY). http://creativecommons.org/licenses/by/4.0/

(c) (i) Open Access

\section{Abstract}

Background: Coagulase negative Staphylococci (CoNS) are normal inhabitants of the skin and mucous membranes and thus have been dismissed for a long time as culture contaminants even if they have been isolated from sterile specimens. The risk factors for CoNS infections include patients who are immunocompromised, implanted with foreign bodies or with indwelling devices. The aim of this study was to determine the antimicrobial susceptibility patterns and presence of mecA gene in methicillin resistant CoNS isolated in a teaching and referral hospital in Kenya. Methodology: This was a cross sectional retrospective study. Archived isolates were sub-cultured on $\mathbf{5 \%}$ sheep blood agar. Speciation and antimicrobial susceptibility patterns were performed by $\mathrm{Vi}$ tek2 technique. The presence of mecA gene was determined by (PCR). Results: A total of seven species were identified with Staphylococcus epidermidis having the highest percentage at $45.4 \%$ and Staphylococcus warneri with the lowest at $2.6 \%$. High resistance to antibiotics that were tested was observed regardless of the source of the isolate. $\mathrm{MecA}$ gene was found in $\mathbf{9 0 \%}$ of the isolates. Conclusion: Coagulase negative Staphylococci exhibited high levels of resistance generally. Most of the isolates carried the mecA gene. Despite some of the isolates being resistant to Cefoxitin, the mecA gene was not found. There is a possibility that methicillin resistance in these isolates is mediated using a different mechanism.

\section{Keywords}

Coagulase Negative Staphylococcus (CoNS), Antimicrobial Susceptibility Patterns, Methicillin Resistance 


\section{Introduction}

In recent years, CoNS isolation in the clinical microbiology laboratory has increased mainly due to the rise in use of prosthetic devices and the invasive vascular technologies in hospitalized patients rendering them important causative agents of nosocomial bacteremia [1]. Biofilm formation enables attachment and persistence of the bacteria, making them inaccessible to the immune system and antibiotics [2] [3].

CoNS have been for a long time dismissed as culture contaminants even if they had been isolated from sterile specimens [4]. However, the potential pathogenicity of CoNS was published in 1958 [4]. The risk factor for CoNS infections include patients who are immunocompromised, implanted with foreign bodies or with indwelling devices. CoNS cause several infections including bacteremia, central nervous system shunt infections, endophthalmitis and foreign body infections [5]. CONS strains that are methicillin resistant are a common cause of hospital acquired infections worldwide [6] [7]. CoNS are usually more resistant to antibiotics than S. aureus. In one study done, the resistance in clinical strains to penicillin was 91\% [8] [9]. In addition to this, it is expensive to treat MR CoNS because of the long duration it takes to be cured and the higher cost of the drugs. Staphylococcus epidermidis, one of the species in CoNS is considered as a major pathogen of nosocomial bacteremia associated with catheter and neonatal sepsis [10].

An uncomplicated urinary tract infection (UTI) in women is caused by Staphylococcus saprophyticus, another species within CONS [11]. A number of complications including recurrent infections, nephrolithiasis, acute pyelonephritis and septicemia have been reported [11]. Males of all ages are infected with Staphylococcus saprophyticus [12]. Contamination of indwelling devices occurs most probably with inoculation of a few microorganisms from the patient's skin or mucosa during the process of implantation [13].

This study aimed to determine the antimicrobial susceptibility patterns and genetic basis for methicillin resistance in archived CoNS obtained from patients seen at the Aga Khan University hospital in Nairobi, Kenya.

\section{Methodology}

Study site: Aga Khan University Hospital, Nairobi.

Study design: A cross sectional retrospective study.

\section{Laboratory Procedures}

\subsection{Culture of the Isolates}

Archived isolates were initially sub-cultured on $5 \%$ sheep blood agar and incubated at $37^{\circ} \mathrm{C}$ overnight. The identity of the isolates was confirmed by standard laboratory methods which included colony morphology; small round white colonies and non heamolytic, gram staining; a drop of sterile water was placed on a clean slide and a loopful of bacteria emulsified and the smear was left to air dry. It was then heat fixed by passing the slide through the flame of a spirit lamp three times and left to cool for some time. It was then covered with crystal violet stain for $1 \mathrm{~min}$ and then rapidly washed off the stain with clean water. The water was tipped off and the smear covered with Lugol's iodine for 1 min. It was washed with clean water, tipped off and decolorized with acetone for few seconds and then covered with neutral red stain for 2 mins. The slide was wiped behind and placed in a draining rack and left to air dry. Catalase test; two drops of hydrogen peroxide were placed on a clean slide. Using a sterile wooden stick, several colonies of the bacteria were picked and immersed in the solution. Immediate bubbling was looked for. Coagulase test; the bacterial suspension was placed on a drop of plasma on the slide and clumping of the organisms was checked within 10 secs. The Vitek2 (bioMérieux, Marcy I’Etoile, France) compact, was used to characterize the CoNS up to species level

\subsection{Antimicrobial Susceptibility Testing}

Antimicrobial susceptibility testing was performed using Vitek2, which uses the principal of Minimum Inhibitory Concentration (MIC). The manufacturer's procedures were followed in preparing the samples for antimicrobial testing. The following antibiotics were tested; Penicillin, Oxacillin, Vancomycin, Teicoplanin, Gentamicin, Tobramycin, Erthromycin, Tetracycline, Moxifloxacin, Levofloxacin, Nitrofurantoin/Mupiciron, Linezolid, Clindamycin and Trimethoprim/Sulfamethoxazole. Methicillin resistance was determined by testing resistance to $30 \mu \mathrm{g}$ Cefoxitin. An inhibition zone of $\leq 21$ was considered as a positive MR CoNS based on the (CLSI Guidelines 2013). 


\subsection{Detection of the mecA Gene}

The DNA was extracted using the boiling method as described;

Day 1

A loopful of the stocked CoNS isolates were picked and sub-cultured on $5 \%$ sheep blood agar at $35^{\circ} \mathrm{C}$ overnight.

Day 2

One to two colonies were emulsified in $5 \mathrm{ml}$ trypticase soy broth (TSB). The inoculated TSB tubes were incubated in a shaking incubator at $68 \mathrm{rpm}$ (New Brunswick Scientific, classic series, C24 incubator shaker) at $37^{\circ} \mathrm{C}$ overnight.

\section{Day 3}

$1 \mathrm{ml}$ of the test organism was put into an eppendorf tube and centrifuged at 10,000 rpm for 5 minutes. The supernatant was discarded. The sedimented cells were re-suspended in $1 \mathrm{ml}$ of TE Buffer and vortexed to mix homogeneously. It proceeded to boiling using the heating block for 30 minutes to relaease the DNA. The suspension was then centrifuged at $15,000 \mathrm{rpm}$ for 10 minutes to separate the DNA. The suspension was then discarded and the supernatant which is considered as the template DNA was stored at $-80^{\circ} \mathrm{C}$ for PCR.

PCR amplifications were performed using a DNA Engine DYAD ${ }^{\mathrm{TM}}$ Peltier Thermal Cycler (MJ Research) using the following reaction conditions; denaturation at $95^{\circ} \mathrm{C}$ for 5 min-1 cycle, annealing at $56^{\circ} \mathrm{C}$ for 30 sec-1 cycle, extension at $72^{\circ} \mathrm{C}$ for $1 \mathrm{~min} / \mathrm{kb}-40$ cylces and final extension $72^{\circ} \mathrm{C}$ for $10 \mathrm{~min}-1 \mathrm{cycle}$. The fol-


$5^{1}$ CTGGAACTTGTTGAGCAGAG $3^{1}$ ). Each PCR reaction included a positive control, which was ATCC 47613, and sterile distilled water as the negative control. The PCR products were electrophoresed on 1\% agarose at 120 volts until the loading dye had travelled 1/2 to 3/4 of the full distance of the gel, about 45 mins -1 hr. The products were stained with $10 \mu \mathrm{M}$ ethidium bromide and DNA fragments were visualized on a UV light box and photographed with Polaroid camera lens with an aperture set at f/11 and exposure time of 30 milliseconds. The positive tests showed a PCR product of $310 \mathrm{bp}$.

\subsection{Ethical Approval}

Ethical clearance to carry out the study was obtained from Kenya Medical Research Institute (KEMRI) Scientific Steering Committee and Ethical Review Committee.

\subsection{Results}

Even though $S$. saprophyticus is the only clinically relevant pathogen to patient population, Antimicrobial resistance in other CoNS has clinical implications for vulnerable hospitalized patients. Most of the CoNS (except $S$. saprophyticus) including blood isolates are considered contaminants from skin and mucosal surfaces yet antimicrobial susceptibility (AST) is performed in routine clinical setting of ICU screening and blood cultures from admitted patients.

\section{Species Distribution}

A total of 196 isolates were revived and the species were distributed as shown in Table 1.

S. epidermidis had the highest number of isolates at $45.4 \%$ with the least being $S$. warneri at $2.6 \%$.

A total of 196 CoNS were recovered and identified. Staphylococcus epidermidis was the commonest species (45.4\%) followed by Staphylococcus saprophyticus (17.5\%), Staphylococcus haemolyticus (15.3\%), Staphylococcus hominis (8.2\%), Staphylococcus ludgunensis (7.7\%), Staphylococcus simulans (3.6\%) and Staphylococcus warneri (2.6\%) All the isolates $\mathrm{n}=196$ (100\%) were identified to species level with the use of the vitek2 equipment.

Antimicrobial susceptibility testing showed that all blood isolates $\mathrm{n}=91$ (100\%) were sensitive to vancomycin, while $\mathrm{n}=83$ (91.2\%) were resistant to penicillin. A high rate (30\%) of antimicrobial resistance to $\beta$-lactam antibiotic (Oxacillin) which is conferred by the mecA gene. A binary logistic regression was performed to compare if there is any statistical difference in the antibiotic susceptibility pattern to the four classes of bacterial isolate origin i.e. blood, body fluid, urine and screening swabs and no statistically significant difference was found in susceptibility to all antibiotics tested. 
The antimicrobial susceptibility pattern was determined by minimum inhibitory concentration (MIC) method. A total of 14 antibiotics were tested and the specimen type grouped in four groups as shown in Figure 1. The bars in the graph represent resistance proportions of the isolates in each specimen type.

Figure 1 shows anti-microbial susceptibility patterns of CoNS isolated from different specimens.

\section{The mecA Gene Results}

60 MR CoNS, 30.6\%, were analyzed for the presence of the mecA gene. Most of the methicillin resistant coagulase negative staphylococci expressed the mecA gene presence. Out of the 60 isolates, 54 isolates $90 \%$ contained the mecA gene. The remaining $10 \%$ which could not express the gene could be harboring other genes that codes for other proteins that induces resistance to beta-lactams.

\section{Discussion}

Various isolates of CoNS were grown from a variety of clinical samples as indicated in Table 1.

The clinical significance of CoNS isolate was determined in each case depending on the patient characteristics such as the hospital area (ICU/HDU/NICU/CCU etc.), comorbid conditions, prior antibiotic use and the source of the sample. Clinical interventions were undertaken with collaboration of the primary physician. For example,

Table 1. Distribution of coagulase negative Staphylococci.

\begin{tabular}{ccc}
\hline Species & No. of Isolates & \% of Isolates \\
\hline S. epidermidis & 89 & 45.4 \\
S. saprophyticus & 34 & 17.4 \\
S. haemolyticus & 30 & 15.3 \\
S. hominis & 16 & 8.2 \\
S. ludgunensis & 15 & 7.7 \\
S. simulans & 7 & 3.6 \\
S. warneri & 5 & 2.6 \\
Total & 196 & 100 \\
\hline
\end{tabular}

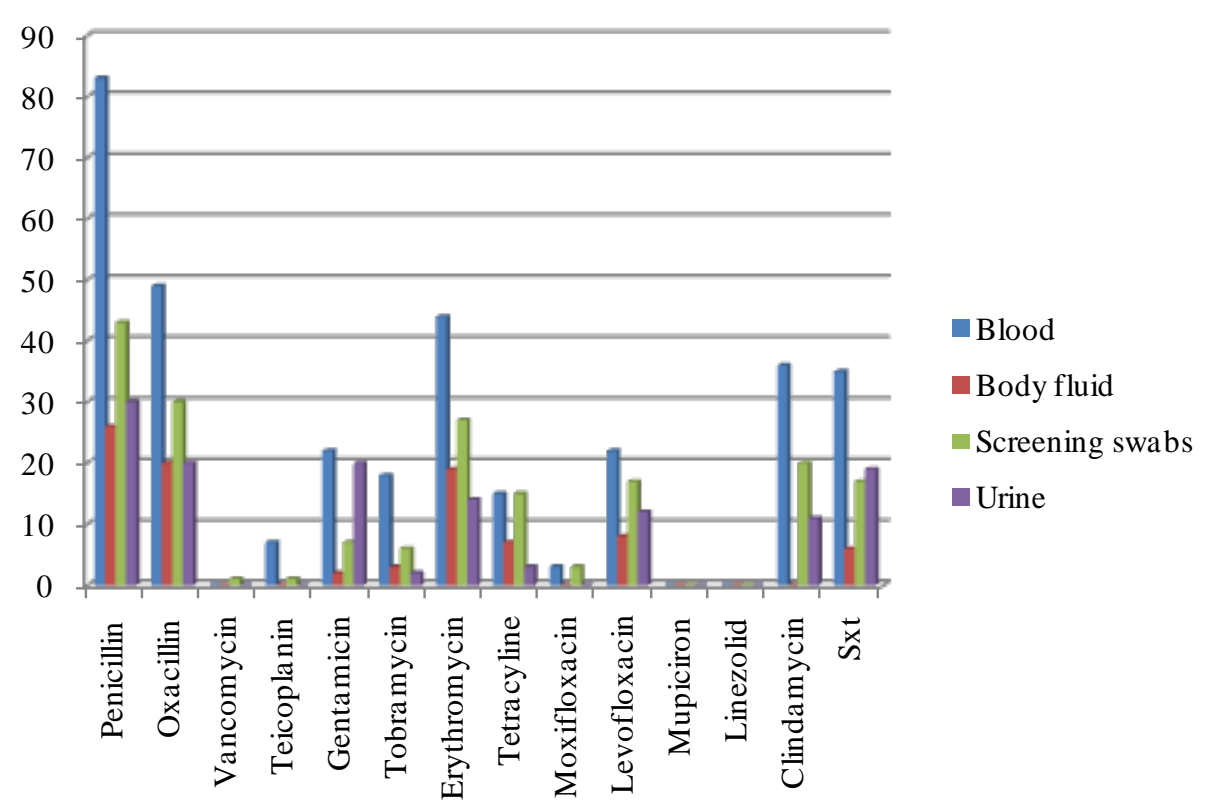

Figure 1. Resistance patterns of CoNS against the tested antibiotics. 
Table 2. Antimicrobial resistance of CONS to various antibiotics.

\begin{tabular}{ccccc}
\hline & $\begin{array}{c}\text { BLOOD (n = 91) } \\
\text { No. (percentage) }\end{array}$ & $\begin{array}{c}\text { BODY FLUID (n = 26) } \\
\text { No. (percentage) }\end{array}$ & $\begin{array}{c}\text { SURVEILLANCE SWABS } \\
\text { (n = 48) No. (percentage) }\end{array}$ & $\begin{array}{c}\text { URINE (n = 31) } \\
\text { No. (percentage) }\end{array}$ \\
\hline Penicillin & $83(91.2 \%)$ & $26(100 \%)$ & $43(89.6 \%)$ & $30(96.8 \%)$ \\
Oxacillin & $49(53.9 \%)$ & $20(73.3 \%)$ & $30(62.5 \%)$ & $20(64.5 \%)$ \\
Gentamicin & $22(24.2 \%)$ & $2(7.7 \%)$ & $7(14.6 \%)$ & $20(64.5 \%)$ \\
Tobramycin & $18(19.8 \%)$ & $3(15.5 \%)$ & $6(12.5 \%)$ & $12(3.5 \%)$ \\
Levofloxacin & $22(24.2 \%)$ & $8(30.8 \%)$ & $17(35.4 \%)$ & $0(0 \%)$ \\
Moxifloxacin & $3(3.3 \%)$ & $0(0 \%)$ & $3(6.25 \%)$ & $14(45.2 \%)$ \\
Erthromycin & $44(48.455)$ & $19(73.1 \%)$ & $27(56.3 \%)$ & $11(35.5 \%)$ \\
Clindamycin & $36(39.6 \%)$ & $0(0 \%)$ & $20(41.8 \%)$ & $0(0 \%)$ \\
Linezolid & $0(0 \%)$ & $0(0 \%)$ & $0(0 \%)$ & $0(0 \%)$ \\
Teicoplanin & $7(7.7 \%)$ & $0(0 \%)$ & $1(2.1 \%)$ & $0(0 \%)$ \\
Vancomycin & $0(0 \%)$ & $0(0 \%)$ & $1(2.1 \%)$ & $3(9.7 \%)$ \\
Tetracyline & $15(16.5 \%)$ & $7(26.9 \%)$ & $15(31.3 \%)$ & $0(0 \%)$ \\
Mupiciron/Nitrofurantoin & $0(0 \%)$ & $0(0 \%)$ & $17(35.4 \%)$ & $19(61.3 \%)$ \\
SXT & $35(38.5 \%)$ & $6(23.1 \%)$ & &
\end{tabular}

in case of blood culture isolate of CoNS, all vascular inserts such as central venous lines, peritoneal dialysis catheters etc. were removed and new lines were inserted. Most of the times, antibiotics did not change because of isolating CoNS from blood.

Patients were covered with additional antibiotics if CoNS was grown from a ventricular shunt which could not be changed. The other instances where CoNS needed antibiotic coverage were isolation from joint prosthesis.

Table 2 shows the resistance patterns of coagulase negative staphylococci against selected antibiotics. Penicillin has the highest percentage of resistance compared to other antibiotics.

Detection of the mecA gene was carried out on 60 isolates which were resistance to Cefoxitin disc. The correlation between the presence of the mecA gene and the phenotypic resistance to methicillin in CoNS is still unwell defined compared to Staphylococcus aureus. A small number of mecA negative CoNS are phenotypically methicillin resistant (Suzuki et al.). These findings were similar to this study in which $90 \%$ of the 60 isolates were MR CoNS and the mecA gene was detected. $10 \%$ of the isolates were MR CoNS but the mecA gene could not be detected. This phenomenon according to (Geha et al., 1994), could be explained by a mechanism in which another non-penicillin-binding protein dependent such as hyper production of $\beta$-lactamase or the presence of other low affinity penicillin-binding proteins could be responsible.

\section{References}

[1] Von Eiff, C., Peters, G. and Heilmann, C. (2002) Pathogenesis of Infection Due to Coagulase Negative Staphylococci. Lancet Infectious Diseases, 2, 677-685. http://dx.doi.org/10.1016/S1473-3099(02)00438-3

[2] Corsterton, J.W., Stewart, P.S. and Greenberg, E.P. (1999) Bacteria Bio-Films: A Common Cause of Persistent Infections. Science, 284, 1318-1322. http://dx.doi.org/10.1126/science.284.5418.1318

[3] Mack, D., Davies, A.P., Harris, L.G., Rohde, H., Horstkotte, M.A. and Knobloch, J.K. (2007) Microbial Interactions in Staphylococcus epidermidis Bio-Films. Annals of Bioanalysis Chemistry, 387, 399-408. http://dx.doi.org/10.1007/s00216-006-0745-2

[4] Smith, I.M., Beals, P.D., Kingsbury, K.R. and Hasencleaver, N.F. (1958) Observations on Staphylococcus albus Septicemia in Mice and Men. Archives of Internal Medicine, 102, 375-388. http://dx.doi.org/10.1001/archinte.1958.00030010375005

[5] Correa, L. and Pittet, D. (2000) Problems and Solutions in Hospital-Acquired Bacteraemia. Journal of Hospital Infec- 
tions, 46, 89-95. http://dx.doi.org/10.1053/jhin.2000.0803

[6] Wisplinghoff, H., Bischoff, T., Tallent, S.M., Seifert, H., Wenzel, R.P. and Edmond, M.B. (2004) Nosocomial Bloodstream Infections in US Hospitals: Analysis of 24,179 Cases from Prospective Nationwide Surveillance Study. Clinical Infectious Diseases, 39, 309-317. http://dx.doi.org/10.1086/421946

[7] Favre, B., Hugonnet, S., Correa, L., Sax, H., Rohner, P. and Pittet, D. (2005) Nosocomial Bacteremia: Clinical Significance of a Single Blood Culture Positive for Coagulase Negative Staphylococci. Infection Control and Hospital Epidemiology, 26, 697-702. http://dx.doi.org/10.1086/502605

[8] Cuevas, O., Cercenado, E., Vindel, A., Guinea, J., Sanchez-Conde, M., Sanchez-Somolinos, M. and Bouza, E. (2004) Evolution of the Antimicrobial Resistant of Staphylococcus spp. in Spain: Five Nationwide Prevalence Studies, 1986 to 2002. Antimicrobial Agents Chemotherapy, 48, 4240-4245. http://dx.doi.org/10.1128/AAC.48.11.4240-4245.2004

[9] Koksal, F., Yasar, H. and Samasti, M. (2007) Antibiotic Resistance Patterns of Coagulase Negative Staphylococcus Strains Isolated from Blood Cultures of Septicemic Patients in Turkey. Microbiological Research, 164, 404-410.

[10] Krediet, T.G., Mascini, E.M., van Rooij, E., Vlooswijk, J., Paauw, A., Gerards, L.J. and Fleer, A. (2004) Molecular Epidemiology of Coagulase Negative Staphylococci Causing Sepsis in a Neonatal Intensive Care Unit over and 11Year Period. Journal of Clinical Microbiology, 42, 992-995. http://dx.doi.org/10.1128/JCM.42.3.992-995.2004

[11] Raz, R., Colodner, R. and Kunin, C.M. (2005) Who Are You-Staphylococcus saprophyticus? Clinical Infectious Diseases, 40, 896-898. http://dx.doi.org/10.1086/428353

[12] Rupp, M.E. and Archer, G.L. (1994) Coagulase-Negative Staphylococci: Pathogens Associated with Medical Progress. Clinical Infectious Diseases, 19, 231-245. http://dx.doi.org/10.1093/clinids/19.2.231

[13] Von Eiff, C., Proctor, R.A. and Peters, G. (2001) Coagulase Negative Staphylococci: Pathogens Have Major Role in Nosocomial Infections. Postgraduate Medicine, 110, 63-76. 
Scientific Research Publishing (SCIRP) is one of the largest Open Access journal publishers. It is currently publishing more than 200 open access, online, peer-reviewed journals covering a wide range of academic disciplines. SCIRP serves the worldwide academic communities and contributes to the progress and application of science with its publication.

Other selected journals from SCIRP are listed as below. Submit your manuscript to us via either submit@scirp.org or Online Submission Portal.
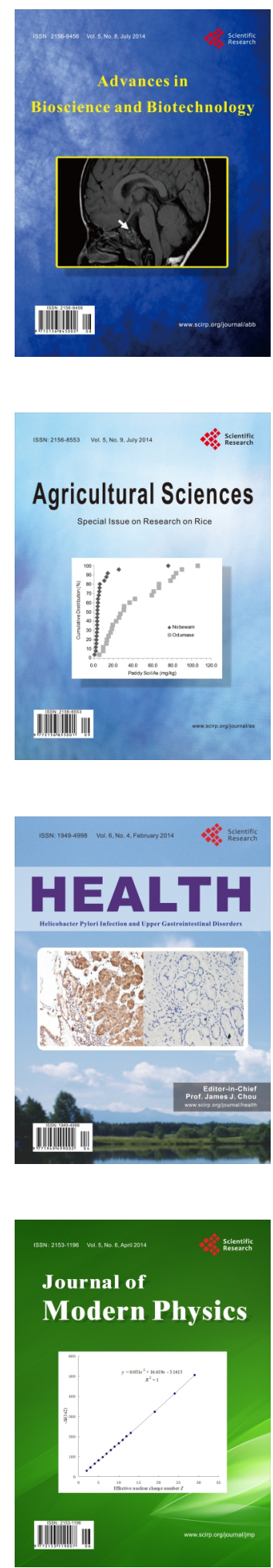
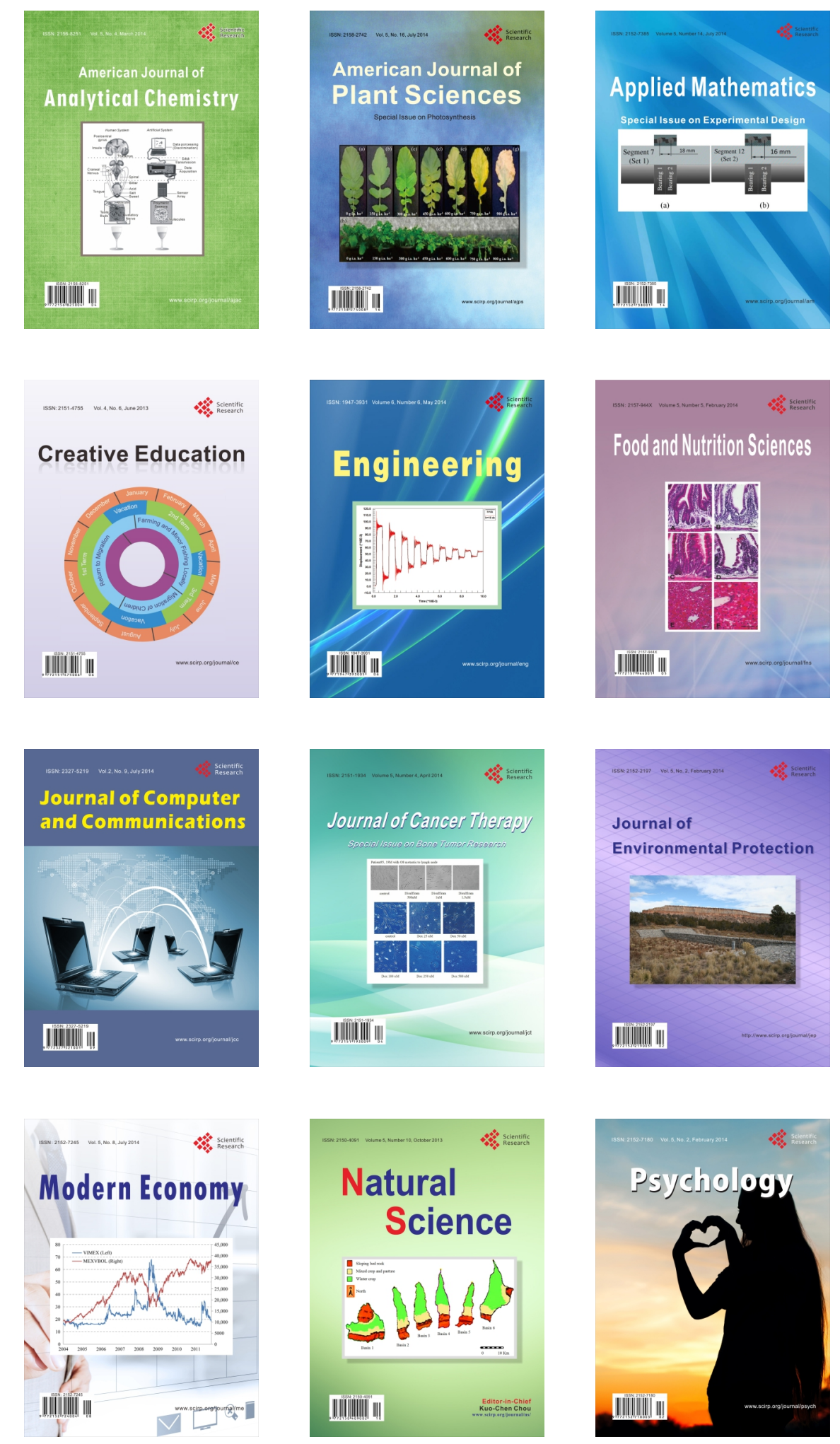